IRA-International Journal of Technology \& Engineering ISSN 2455-4480; Vol.05, Issue 01 (2016)

Pg. no. $18-21$

Institute of Research Advances

http://research-advances.org/index.php/IRAJTE

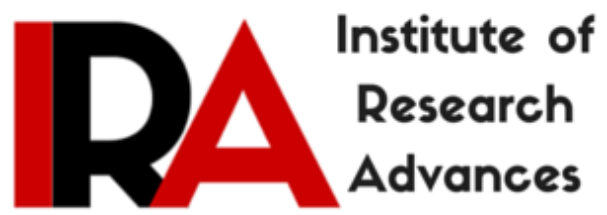

\title{
The Mathematical Analysis On The Effect Of Strong Nonlinearity On Steady-State Self- Focusing And Filamentation Of Whistlers In A Plasma
}

\section{Ghanshyam}

Department of Physics, BIT, Sindri, Dhanbad-828123, India.

Type of Reviewed: Peer Reviewed.

DOI: http://dx.doi.org/10.21013/jte.v5.n1.p4

\section{How to cite this paper:}

Ghanshyam (2016). The Mathematical Analysis On The Effect Of Strong Nonlinearity On Steady-State Self-Focusing And Filamentation Of Whistlers In A Plasma. IRAInternational Journal of Technology \& Engineering (ISSN 2455-4480), 5(1), 18-21. doi:http://dx.doi.org/10.21013/jte.v5.n1.p4

(C) Institute of Research Advances

(c) EY-NC

This work is licensed under a Creative Commons Attribution-Non Commercial 4.0 International License subject to proper citation to the publication source of the work.

Disclaimer: The scholarly papers as reviewed and published by the Institute of Research Advances (IRA) are the views and opinions of their respective authors and are not the views or opinions of the IRA. The IRA disclaims of any harm or loss caused due to the published content to any party. 


\begin{abstract}
A high-power Gaussian Whistler propagating in a magnatoplasma becomes self-focused because of (i) ponderomotive force and (ii) nonuniform heating nonlinearities (i) being dominant for $t$ $\ll T$ and (ii) being dominant for $t>t_{E}$. On short time scale $\left(t<t_{E}\right)$ whistlers of all frequencies can be focused (the self-focusing length is very large for $\omega=\omega_{c} / 2$ and decreases rapidly on both sides), whereas on the long time scale $\left(t>t_{E}\right)$ only high frequency whistlers $\left(\omega>\omega_{c} / 2\right)$ are focused. At very high powers the plasma is depleted almost completely from the axial region and self-focusing does not occur, rather, defocusing takes place.

A plane uniform whistler of high intensity is seen to be unstable for small scale fluctuations, i.e., it must break up into filaments in course of it propagation. The growth rate increases with decreasing scale length of perturbation and is seen to be a saturating function of power density of the beam.
\end{abstract}

\title{
01. Introduction
}

Self-focusing and filamentation instability of electromagnetic waves is recognized as an important nonlinear process in laboratory and space plasmas having consequences for stimulated scattering, absorption and other phenomena ${ }^{1,6,8}$. In series of exeperiments ${ }^{9-11}$ Stenzel has observed the filamentation of a high power whistler in laboratory plasma.

In the presence of a high-power Gaussian whistler, the electrons of the plasma are redistributed in the transverse direction (i.e., perpendicular to the axis of the beam) became of (i) ponderomotive force and (ii) nonuniform heating. On the time scale $\mathrm{t}<<\tau_{h}$, where $\tau_{h}$ is the heating time of electrons, the nonlinearly responsible for this phenomenon arises through the ponderomoforce on electrons. For $\mathrm{t}>\tau_{h}$ the nonlinearity arises through nonuniform heating and redistribution of electrons. Present analysis shows that on the short time scale the self-focusing of whistlers is not possible for all frequencies, whereas on the long time scale only those whistlers can be self-focused for which $\omega>\omega_{c}$ 12 ;lower - frequency whistlers on the long time scale suffer enhanced divergence due to strong nonlinearity. The growth of a small perturbation in the intensity distribution of a high-power whistler has also been investigated and the breaking up of the whistler into filaments is discussed.

\section{Self-Focusing : Strong Nonlinearly}

Let us consider the propagation of a high power whistler in a magnetoplasma along the direction of the static magnetic field Bo, i.e. the $\mathrm{Z}$ axon's. The frequency of the whistler is in the range $\omega<\omega_{\mathrm{c}}<<\omega_{\mathrm{p}}\left(\omega_{\mathrm{p}}\right.$ being the equilibrium plasma frequency) and the electric vector is right handed circularly polarized, i.e., $\mathrm{E}_{\mathrm{x}}=\mathrm{iE}_{\mathrm{y}}$. The tram-verse intensity distribution of the beam at $\mathrm{z}=0$ is given by

$$
\left.A_{1} A_{1}^{*}\right|_{\mathrm{z}=0}=E_{0}^{2} \exp \left(-r^{2} / r_{0}^{2}\right)
$$

Where $A_{1}=E_{x}+i E_{y}$ and $r$ refers to a cylindrical coordinate system.

In the presence of the whistler, plasma is redistributed in the radial direction and the dielectric tensor becomes a nonlinear function of $\mathrm{A}_{1} A_{1}^{*}$ Following Sodha, Ghatak, and Tripathi, the intensity distribution may be written as

$$
A_{1} A_{1}^{*}=\frac{E_{0}^{2}}{f^{2}(z)} \exp \left(-\frac{r^{2}}{r_{0}^{2} f^{2}(2)}\right),
$$

Where $\mathrm{f}$, the beamwidth parameter is governed by 
$\frac{d^{2} f}{d_{z 2}}=\frac{1}{R_{d 0}^{2} f^{3}}+\frac{\omega_{p}^{2} F}{\omega\left(\omega_{c}-\omega\right) r_{0}^{2} f^{3}}$

Where $\mathrm{R}_{\mathrm{do}}=\frac{\omega}{c} r_{0}^{2}$, being the diffraction divergence length and

$\mathrm{F}=\propto_{1} \exp \left(-{ }^{\alpha_{1} E_{0}^{2}} / f^{2}\right)$

For ponderomotive nonlinearity (valid only for $\omega>\frac{1}{2} \omega_{c}$, i.e., $\alpha_{1}$ being + ve )

$\mathrm{F}=\propto_{2} /\left(1+{ }_{2} E_{0}^{2} / f^{2}\right)$

For heating nonlinearity (valid for all $\omega$ ). It is evident from Eq. (3) that the second term on the right hand side, the term due to nonlinearity, cases divergence of the beam for $\omega>\omega_{c}$. Thus one may conclude that very-high- power whistlers $\left(\omega<\omega_{c}\right)$ suffer enhanced divergence due to nonlinearity.

\section{Filamentation Instability}

Whistler of sufficiently high power has a tendency to concentrate energy around intensity maximum. A small intensity fluctuation over a uniform beam should grow in course of its propagation, i.e., the beam in course of its propagation in plasma should break into filaments. The earlier analysis, of filamentation instability is applicable only to high frequency waves in isotropic plasmas. Here, filamentation instability of a plane uniform whistler in a magnetoplasma. For the sake of mathematical simplicity, the frequency range $\omega<\omega_{c}<\omega_{p}$ is considered. This range is very important form the point of view of ionospheric whistlers.

Consider the propagation of a Home uniform whistler in a magnetoplasma in the direction of static magnetic field. The circularly polarized electric vector of the wave may be expressed as

$\mathrm{E}_{\mathrm{ox}}+\mathrm{i} \mathrm{E}_{\mathrm{oy}}=\mathrm{A}_{10} \exp \mathrm{i}\left(\omega \mathrm{t}-\mathrm{k}_{\mathrm{o}} \mathrm{z}\right)$,

$\mathrm{E}_{\mathrm{ox}}-\mathrm{iE}_{\mathrm{oy}}=0, \mathrm{E}_{\mathrm{oz}}=0$,

Where $\mathrm{k}_{\mathrm{o}}=(\omega / c) \varepsilon_{0+}^{1 / 2}$

Over this uniform beam a perturbation $\mathrm{E}_{1}\left(\mathrm{x}_{1}, \mathrm{z}\right) \exp \left[\mathrm{i}\left(\omega \mathrm{t}-\mathrm{k}_{\mathrm{o}} \mathrm{z}\right)\right]$ is superimposed. Where $\mathrm{E}_{1}\left(\mathrm{x}_{1}, \mathrm{z}\right)$ is not necessarily a slowly varying function of space variables. The total electric vector of the whistler may now be written as

$\mathrm{E}_{\mathrm{x}}+\mathrm{i} \mathrm{E}_{\mathrm{y}}=\left(\mathrm{A}_{10}+\mathrm{A}_{1}(\mathrm{x}, \mathrm{z})\right) \exp \left[\mathrm{i}\left(\omega \mathrm{t}-k_{0} \mathrm{z}\right)\right]$

$\mathrm{E}_{\mathrm{x}}-\mathrm{iE}_{\mathrm{y}}=\mathrm{A}_{\mathrm{z}}(\mathrm{x}, \mathrm{z}) \exp \left[\mathrm{i}\left(\omega \mathrm{t}-k_{0} z\right)\right]$

and

$\mathrm{E}_{\mathrm{z}}=\mathrm{E}_{\mathrm{z} 1}(\mathrm{x}, \mathrm{z}) \exp \left[\mathrm{i}\left(\omega \mathrm{t}-k_{0} \mathrm{z}\right)\right]$,

Where $A, A_{z}$ and $E_{z 1}$ are first order quantities. Following Sodha, Ghatak, and Tripathi ${ }^{7}$ [Eq. (2.6.1)] the ponderomotive force on electrons may now be obtained as

$\mathrm{F}_{\mathrm{p}}=-2 \alpha_{1} \mathrm{k}_{\beta} \mathrm{T}_{\mathrm{o}} \nabla\left(\mathrm{A}_{1}+A_{1}^{*}\right) \mathrm{A}_{10}$

To obtain the spatial growth of perturbation, we solve the linearized wave equation

$\nabla^{2} \mathrm{E},-\nabla\left(\nabla \cdot \mathrm{E}_{1}\right)=-\frac{\omega^{2}}{c^{2}}\left[\epsilon_{\mathrm{L}} \cdot \mathrm{E}_{1}+\left(\in-\epsilon_{\mathrm{L}}\right) \cdot E_{0}\right]$, 
Where $\epsilon_{\mathrm{L}}$ is dielectric tensor in absence of perturbation.

Following Sodha, Ghatak, and Tripathi one may obtain

$k_{z}^{2}=+\frac{2 \propto_{1} A_{10}^{2}\left(2 k_{x}^{2}+\frac{1}{2} k_{x}^{4}\right)+\frac{1}{4} k_{x}^{4}}{-2 \propto_{1} A_{10}^{2}\left(\frac{1}{2} k_{x}^{4}+2 k_{x}^{4}+4\right)+16+4 k_{x}^{2}-2 k_{x}^{4}}$

It must be remembered that $\mathrm{k}_{\mathrm{n}}$ and $\mathrm{k}_{\mathrm{z}}$ are dimensionless quantities as they are expressed in units of $\mathrm{k}_{0}$. Also, $\alpha_{1}$ is negative; Equation (12) shows that for high values of $\left|\propto_{1}\right| A_{10}^{2}, k_{z}^{2}$ may become negative, i.e. the perturbation would grow as it propagates in the $\mathrm{z}$ direction. The threshold for the growth of perturbation can be abstained from Eq. (12) as

$A_{10 t h}^{2}=-\frac{k_{x}^{4}}{\alpha_{1}\left(16 k_{x}^{2}+4 k_{x}^{4}\right)}$.

To have an explicit nature of variation of growth rate $\gamma_{\mathrm{z}}\left(=\mathrm{ik}_{\mathrm{z}}\right)$ with the intensity of the beam. Eq.(12) has been solved numerically.

\section{$\underline{\text { Discussion and conclusions }}$}

A high - power Gaussian whistler propagating in a magnetoplasma becomes self-focused because of (i) ponderomotive force and (ii) non uniform heating nonlinearities; (i) being dominant for $\mathrm{t}<<\mathrm{t}_{\mathrm{E}}$ and (ii) being dominant for $\mathrm{t}>>\mathrm{t}_{\mathrm{E}}$. At very high powers the plasma is depleted almost completely from the axial region and self - focusing does not occur; rather, defocusing takes place.

A plane uniform whistler of his intensity is seen to be unstable for small-scale fluctuations, i.e., it must break up into filaments in course of its propagation. The growth rate increases with decreasing scale length of perturbation and is seen to be a saturating function of power density of the beam.

\section{REFERENCES :}

1. AFSHAR-RAD, T., COE, S.E., WILLI,O. and DESSELERGER, M. 1992 Phys. Fluids 4, 1301.

2. JONES, R.D., MEAD, W.C., COGGESHALl, S.V., ALDRICH, C.H., NORTAN, J.L. POLLAK, G.D. WALLACE, J.M. 1988 Phys. Fluids 31, 1249.

3. KAW, P.K. SCHMIDF, G. and WILCOX, T. 1973. PHYs. Fluids 16, 1522.

4. KRER, W.L., 1984 Phys. Rev. Lett. 53,1939.

5. LAXMI, V.N. and TRIPATHI, V.K. 1988 Radio sci 32,945.

6. LIU, C.S. and TRIPATHI, V.K. 1986 phys. Fluids 29, 4188.

7. SODHA, M.S., GHATAK, A.K. and TRIPATHI, V.K. 1976 Prog. Opt. 13, 169.

8. SODHA, M.S., PATEL, L.A. and SHARMA, R.P. 1978 J Appl. Phys, 49, 3707.

9. STENZEL, R.L. 1976 Phys. Fluids 19,865.

10. STENZEL, R.L. 1976 Phys. Fluids 19,857.

11. STENZEL, R.L. 1975 Phys. Rev. Lett. 35,574. 